\title{
New perspectives on inhaled drug delivery and systemic bioactivity
}

The inhaled route of administration is widely accepted as being the optimal way of giving drugs such as corticosteroids and $\beta_{2}$ agonists for the treatment of patients with airflow obstruction. It is possible with the inhaled route to deliver relatively small doses of drug to produce high local concentrations in the airway, and at the same time minimise absorption into the systemic circulation. There are some patients with more severe airflow obstruction who may benefit from higher than conventional doses of inhaled corticosteroid and $\beta_{2}$ agonist, and indeed this practice appears to have gained widespread acceptance amongst many respiratory physicians. Whilst higher doses of these drugs may produce an improved airway response, it is well recognised that there is also a dose-response relationship in terms of systemic adverse effects, both for inhaled corticosteroids and for $\beta_{2}$ agonists. ${ }^{12}$ The factors which determine systemic absorption from the gut and lung have been given little consideration. In this respect there are now an increasing number of new inhaler delivery systems which are designed to optimise lung deposition, and it is therefore important to know how this might alter the systemic bioavailability. The spectrum of systemic adverse effects of inhaled corticosteroids and $\beta_{2}$ agonists will not be discussed further in this article as they have been extensively reviewed elsewhere. ${ }^{1-4}$

\section{Factors determining systemic bioactivity}

In general terms systemic bioactivity will be determined by pharmacokinetic and pharmacodynamic properties of the drug concerned and its inhaler delivery system. Systemic bioavailability of inhaled drugs may arise from absorption from the gastrointestinal tract or the lung. The systemic bioavailability from gut and lung vascular beds will, in turn, be determined by the respective first-pass metabolism prior to absorption. Furthermore, systemic absorption across the mucosal barrier will also depend on the relative lipid solubility of the drug being delivered. Once the drug has been absorbed into the systemic circulation its rate of elimination will determine its clearance from the circulation and hence its half life. The pharmacodynamic factors determining systemic bioactivity are the affinity and potency of the drug at its receptor site of action. The ensuing discussion will focus primarily on pharmacokinetic factors rather than pharmacodynamic factors.

\section{Gastrointestinal bioavailability}

Most of the nominal dose leaving an inhaler device (approximately $80 \%$ ) is deposited in the oropharynx which is endowed with a rich vascular network but has a relatively small surface area available for systemic absorption. Drug absorption across the buccal mucosa occurs directly into the systemic circulation and avoids first-pass hepatic or intestinal metabolism. Absorption from the buccal cavity will depend on the degree of lipid solubility and ionisation (pKa) as well as the prevailing $\mathrm{pH}^{5}$ The polarity and poor lipid solubility of salbutamol when given sublingually explain why there is negligible absorption from this route. ${ }^{6}$ In support of this, Collier and coworkers ${ }^{7}$ showed that the systemic $\beta_{2}$-mediated effects of metered doses of salbutamol aerosol occur only when it is inhaled into the lung, but not when it is sprayed directly into the buccal cavity. Likewise, other clinical studies have shown that mouth rinsing and the use of a large volume spacer do not attenuate systemic $\beta_{2}$ effects of inhaled salbutamol. ${ }^{89}$ Thus, systemic absorption of inhaled salbutamol occurs predominantly from the vascular bed of the lung rather than the gut. The pharmacokinetic plasma profile for inhaled salbutamol would also support lung vascular absorption as the maximum plasma concentration is achieved within five minutes, which is similar to that following an intravenous injection. The fraction of salbutamol which reaches the intestine after swallowing undergoes extensive first-pass sulphate conjugation, probably in the intestinal mucosa itself. $^{10}$

For inhaled corticosteroids the situation is somewhat different. Firstly, the high degree of lipid solubility would be expected, on first principles, to be associated with significant buccal absorption. The degree of buccal absorption is, however, probably limited by the small available absorptive surface area as well as the relatively short mucosal exposure time before swallowing occurs. Whilst buccal absorption of inhaled corticosteroids avoids first-pass metabolism, absorption from the intestine undergoes an extensive degree of first-pass hepatic metabolism. The firstpass metabolism for oral beclomethasone dipropionate is approximately $80 \%$, for budesonide $89 \%$, and for fluticasone propionate $99 \% .{ }^{11-13}$ Whilst beclomethasone dipropionate is biotransformed to its active metabolite (17beclomethasone monopropionate) in the lung, there is no known first-pass biotransformation of either budesonide or fluticasone propionate. This, in turn, will clearly influence the total systemic bioavailability of budesonide and fluticasone in terms of the relative components of lung and gut absorption.

The effect of mouth rinsing on the oral bioavailability of budesonide has been studied in some detail. Selroos and coworkers ${ }^{14}$ showed that the use of mouth rinsing with water after inhalation of budesonide Turbohaler $1.6 \mathrm{mg}$ resulted in a $15 \%$ mean reduction in systemic bioavailability as assessed by suppression of early morning cortisol levels. 


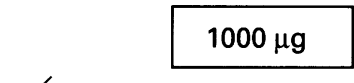

Gut $50 \%$

Lung $20 \%$
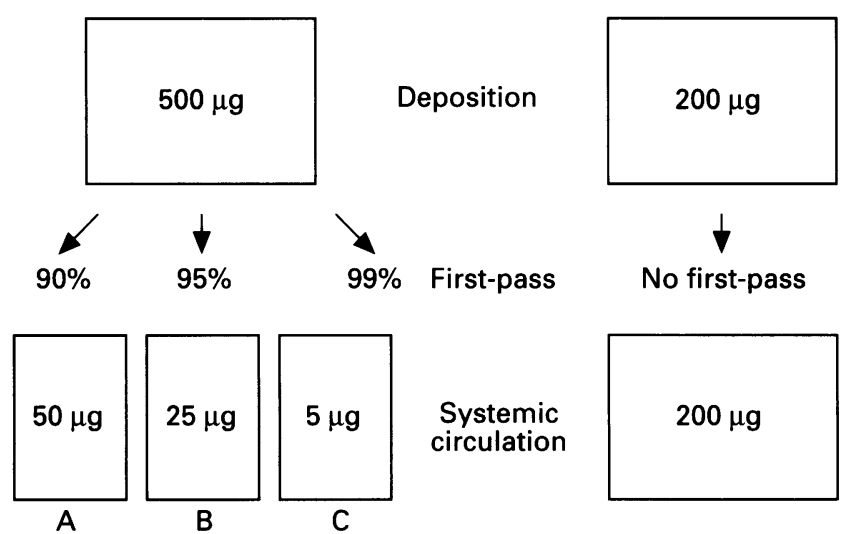

Figure 1 Schematic representation of systemic bioavailability of three hypothetical inhaled corticosteroids $(A, B$, and $C$ ) in a dose of $1000 \mu \mathrm{g}$ given by the same inhaler device, each with different degrees of hepatic first-pass metabolism, but with no first-pass in the lung. The figures for total systemic bioavailability (ung plus gut) and percentage lung bioavailability (ung/total) are: A $250 \mu \mathrm{g}(80 \%) ; B 225 \mu \mathrm{g}$ (89\%); C $205 \mu \mathrm{g}(98 \%)$.

A

Fluticasone Diskhaler $1000 \mu \mathrm{g}$

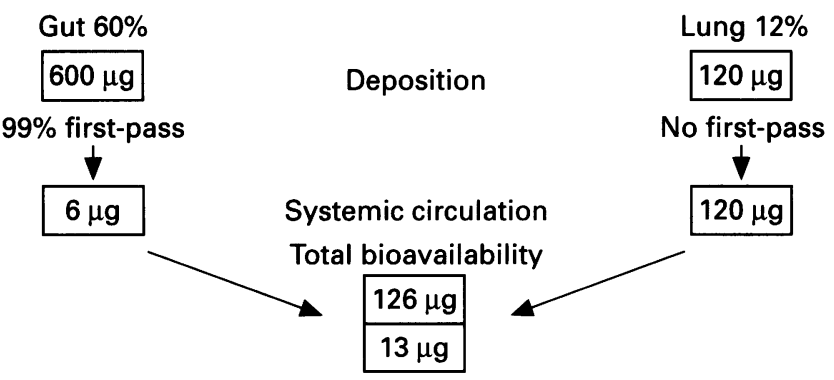

B

Budesonide Turbohaler $1000 \mu \mathrm{g}$

Gut $56 \%$

Lung $27 \%$

$560 \mu \mathrm{g}$

Deposition

$270 \mu \mathrm{g}$

$89 \%$ first-pass

$\stackrel{\downarrow}{\downarrow} \mu \mathrm{g}$

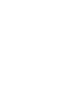

Systemic circulatio

Total bioavailability

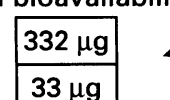

Figure 2 Schematic representation of systemic bioavailability of $(A)$ fluticasone propionate and (B) budesonide given by respective dry powder inhaler devices. Approximate data for lung and gut deposition of Diskhaler and Turbohaler in normal subjects are taken from refs 16 and 28, and for hepatic first-pass from refs 12 and 13 .

This figure is similar to that reported by Pedersen et $a l^{15}$ in a pharmacokinetic study measuring plasma budesonide levels, where mouth rinsing and swallowing of a charcoal suspension (so called charcoal block) resulted in an approximately $20 \%$ reduction of the total systemic bio- availability of budesonide Turbohaler $1 \mathrm{mg}$. The inference from these two studies is that mouth rinsing should be routinely employed when using dry powder inhaler devices such as the Turbohaler or Diskhaler, not only to reduce oral bioavailability, but also to reduce the propensity for producing local adverse effects such as oropharyngeal candidiasis. The effects of large volume spacer devices on systemic bioavailability will be discussed below because this will be dependent on the relative effects of the spacer on oral and lung bioavailability.

\section{Lung bioavailability}

On the basis of the data from mouth rinsing and charcoal block studies ${ }^{14}{ }^{15}$ it can be inferred that the systemic bioavailability of inhaled corticosteroids is mainly determined by absorption across the lung vascular bed. In other words, although the greater part of an inhaled steroid dose is absorbed from the gut, it is mostly inactivated by first-pass metabolism. It would also follow, therefore, that an inhaler delivery system which improves lung deposition would, at the same time, be expected to increase lung bioavailability and hence overall systemic absorption.

Let us consider as a working example the relative gut versus lung components of systemic bioavailability for three different inhaled corticosteroids given in a dose of $1000 \mu \mathrm{g}$ via the same delivery system (fig 1). For the purposes of this example the percentages for lung and gut deposition have been rounded up to $20 \%$ and $50 \%$ respectively, with the data being taken from the study of Melchor et $a l^{16}$ for a metered dose inhaler using the technetium labelling method for salbutamol. It is clearly evident from these calculations that, even when hepatic first-pass metabolism is increased beyond $90 \%$, there is relatively little impact on the total systemic bioavailability of each of the three inhaled corticosteroids. This once again indicates that it is lung bioavailability which is the most important determinant of total systemic bioavailability for drugs such as budesonide and fluticasone propionate which have extensive first-pass hepatic metabolism. As a consequence of this, inhaler devices which improve lung deposition will increase systemic bioavailability to a proportionately greater degree because of the absence of any first-pass effect in the lung. It should, however, be pointed out that the above calculations are only approximate for two reasons. Firstly, any direct buccal absorption into the systemic circulation has not been taken into account. Secondly, it has been assumed that lung bioavailability will be $100 \%$ of the nominal dose delivered to the lungs. Indeed, it is unclear as to the relative proportions entering the systemic circulation via the alveolar capillary bed compared with the bronchial circulation. In addition, no allowance has been made for the proportion of swallowed drug which is unabsorbed from the gut.

On the basis of these calculations it is interesting to compare the relative systemic bioavailability of inhaled fluticasone propionate and budesonide given via dry powder inhaler devices, namely the Diskhaler and Turbohaler (fig 2A, B). If these inhaler devices were used in conjunction with mouth rinsing, thus effectively obviating oral bioavailability, one might predict that the systemic lung bioavailability would be at least twice as high with budesonide as with fluticasone for a given nominal dose of $1000 \mu \mathrm{g}$ that is, $270 \mu \mathrm{g}$ versus $120 \mu \mathrm{g}$. In this respect, two recent studies have evaluated the single dose and steady state systemic bioavailability of budesonide Turbohaler and fluticasone Diskhaler in normal volunteers. In a single dose ranging study reported by Grahnén et $\mathrm{al}^{17}$ the effects of single inhaled doses of fluticasone propionate and budesonide were evaluated in terms of suppression of the 
area under the plasma cortisol levels versus time curve for 0-20 hours $\left(\mathrm{AUC}_{0-20}\right)$ after drug administration. The percentage suppression from placebo was $8 \%$ for fluticasone $250 \mu \mathrm{g}, 19 \%$ for fluticasone $500 \mu \mathrm{g}$, and $28 \%$ for fluticasone $1000 \mu \mathrm{g}$, in comparison with $16 \%$ for budesonide $800 \mu \mathrm{g}$. A further evaluation after seven doses of fluticasone propionate $1000 \mu \mathrm{g}$ twice daily resulted in $65 \%$ suppression of cortisol $\mathrm{AUC}_{0-20}$. These results are clearly consistent with the hypothesis that absorption of fluticasone across the lung vascular bed occurs in a dose-related fashion, since the hepatic first-pass metabolism is close to $100 \%$. Furthermore, since mouth rinsing was employed in the study, buccal absorption was not responsible for producing the systemic bioavailability which occurred. There also appears to be a difference in the degree of adrenal suppression between single and repeated dosing, although this may simply be a reflection of the greater total daily dose given during the chronic dosing period $(2000 \mu \mathrm{g}$ daily) compared with single dosing ( $1000 \mu \mathrm{g}$ daily).

In a study by Grove and coworkers ${ }^{18}$ a randomised crossover design was used to compare budesonide $800 \mu \mathrm{g}$ daily given for one week followed by a further week of $1600 \mu \mathrm{g}$ daily, or fluticasone propionate $750 \mu \mathrm{g}$ daily for one week followed by $1500 \mu \mathrm{g}$ daily for one week. There was a one week washout between treatments with either fluticasone Diskhaler or budesonide Turbohaler which were both administered with mouth rinsing. Both fluticasone and budesonide produced comparable suppression of the tetracosactrin cortisol. response, with significant attenuation occurring at the lower dose. There was, however, no significant suppression of early morning cortisol or plasma osteocalcin levels with either drug. The findings of significant adrenal suppression with low doses of fluticasone and budesonide despite the use of mouth rinsing would therefore infer that absorption across the lung vascular bed was the major determinant of systemic bioactivity for both of these inhaled corticosteroid drugs. Indeed, this would be in keeping with data from Bain et $a l^{19}$ who, using a radioimmunoassay, demonstrated significant circulatory levels of fluticasone following inhalation of $1000 \mu \mathrm{g}$ by metered dose inhaler in normal subjects, with a pharmacokinetic profile in keeping with rapid absorption from the lung rather than from the gut.

On the assumption that the lung bioavailability of fluticasone propionate Diskhaler is $120 \mu \mathrm{g}$ and that of budesonide Turbohaler is $270 \mu \mathrm{g}$ (fig 2), the data on adrenal suppression from the above two studies ${ }^{17} 18$ would suggest that fluticasone propionate exhibits greater systemic glucocorticoid activity than budesonide when appropriate corrections are made for differences in lung deposition between the two devices. This is in contrast to their equivalent topical glucocorticoid potency as assessed by the vasoconstrictor assay, in that two separate studies have shown both drugs to have twice the potency of beclomethasone dipropionate, ${ }^{2021}$ with a further study showing the same potency in a direct comparison between the two drugs. ${ }^{22}$ It would therefore be meaningful to compare the systemic bioactivity of fluticasone propionate and budesonide given via the same inhalation device - for example, a metered dose inhaler - as this would obviate differences in lung bioavailability between the two dry powder devices.

Larger multicentre studies in patients with moderate to severe asthma comparing high doses of fluticasone propionate and beclomethasone dipropionate given by metered dose inhaler have revealed conflicting results regarding their relative systemic bioactivity. Fabbri et $a l^{3}$ found no significant differences in morning plasma cortisol levels, tetracosactrin response, or urinary free cortisol levels when comparing fluticasone propionate $1.5 \mathrm{mg} /$ day with beclomethasone dipropionate $1.5 \mathrm{mg} /$ day. Bakke et $a l^{4}$ reported a significant fall in plasma cortisol (from 360 to $226 \mathrm{nmol} / \mathrm{l}$ ) and ACTH levels (from 34 to $22 \mathrm{ng} / \mathrm{l}$ ) with fluticasone propionate $2 \mathrm{mg} /$ day, whereas adrenal suppression was not detected with beclomethasone dipropionate $1.6 \mathrm{mg} /$ day. Finally, Barnes and coworkers ${ }^{25}$ demonstrated a 1.3-fold greater dose ratio for plasma cortisol suppression with beclomethasone dipropionate despite a twofold difference in dose between fluticasone propionate $(1 \mathrm{mg} /$ day) and beclomethasone dipropionate (2 mg/day).

\section{Pharmacokinetic evaluation of lung deposition}

Initial attempts at evaluating inhaled drug deposition involved the use of technetium- $99 \mathrm{~m}$ labelled Teflon microspheres which were loaded into a pressurised aerosol canister. After inhalation the proportion of radiolabelled particles deposited in the lungs and oropharynx could then be quantified using a gamma camera detection system. ${ }^{26}$ This technique has subsequently been refined using direct labelling of the drug with technetium. In one such study in asthmatic patients the mean total lung deposition of radiolabelled salbutamol was calculated at $18 \%$ for a metered dose inhaler and $11 \%$ for the Diskhaler dry powder device. ${ }^{16}$ Similar figures have also been obtained for asthmatic subjects using radiolabelled salbutamol from another laboratory with $19 \%$ deposition for a metered dose inhaler and $18 \%$ for the Autohaler breath activated device. ${ }^{27}$ There are, however, few available data on lung deposition of inhaled corticosteroids. In a study reported by Borgstrom et $a l^{8}$ using technetium- $99 \mathrm{~m}$ labelled terbutaline and budesonide delivered by a Turbohaler, the respective figures for total lung deposition for both drugs given by the same device in normal subjects were equivalent at $27 \%$ and $28 \%$ respectively. This suggests that the relative lipophilicity of these compounds does not materially affect lung deposition, at least as assessed with the radiolabelled technique.

More recently the pharmacokinetic approach has also been applied to evaluate lung deposition on the assumption that peripheral lung deposition is associated with absorption into the systemic circulation across the alveolar vascular bed. The direct pharmacokinetic technique is dependent, by definition, on the availability of a sufficiently sensitive bioassay for measuring low plasma concentrations of a drug which are found with the inhaled route of administration. Another more indirect pharmacokinetic method using salbutamol involves the measurement of early 30 minute urinary excretion of the native drug and its sulphate metabolite in order to differentiate between lung and gut bioavailability. ${ }^{29}$ The hypothesis that rapid absorption across the lung vascular bed occurs is in keeping with the pharmacokinetic time profile of inhaled $\beta_{2}$ agonists such as salbutamol and fenoterol, in that there is a rapid absorption phase with peak plasma concentrations being achieved within five minutes. ${ }^{30}$ By calculating pharmacokinetic parameters, such as maximum plasma concentration and area under the concentration-time curve, it is possible to make comparisons between different inhaler devices used for delivering the same drug.

For example, in a study comparing a standard metered dose inhaler and modified low velocity actuator device it was found that the systemic absorption of inhaled salbutamol was significantly greater with the modified actuator device in terms of both peak levels and area under curve (fig 3). ${ }^{31}$ The increased salbutamol absorption which occurred with the modified actuator was, in turn, associated with a left shift in the dose-response curve of systemic $\beta_{2}$ mediated effects (fig 4). The difference in lung bio- 


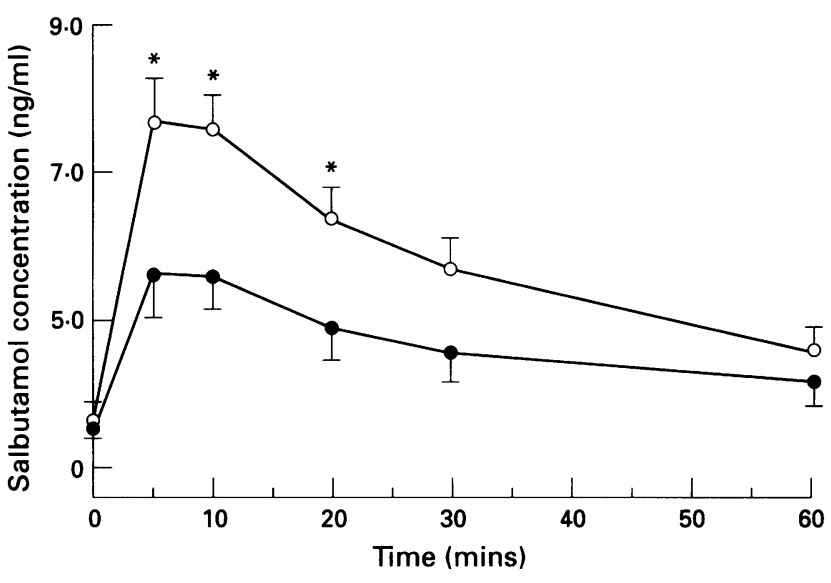

Figure 3 Plasma salbutamol concentration-time profile before and 60 minutes after inhalation of the final cumulative dose of salbutamol $(2600 \mu \mathrm{g})$ given by standard metered dose inhaler (O) and by a modified low velocity actuator device (O). Asterisks denote a significant difference between the two curves. Taken from ref 31 with permission from Blackwell Scientific Publications, Oxford, UK
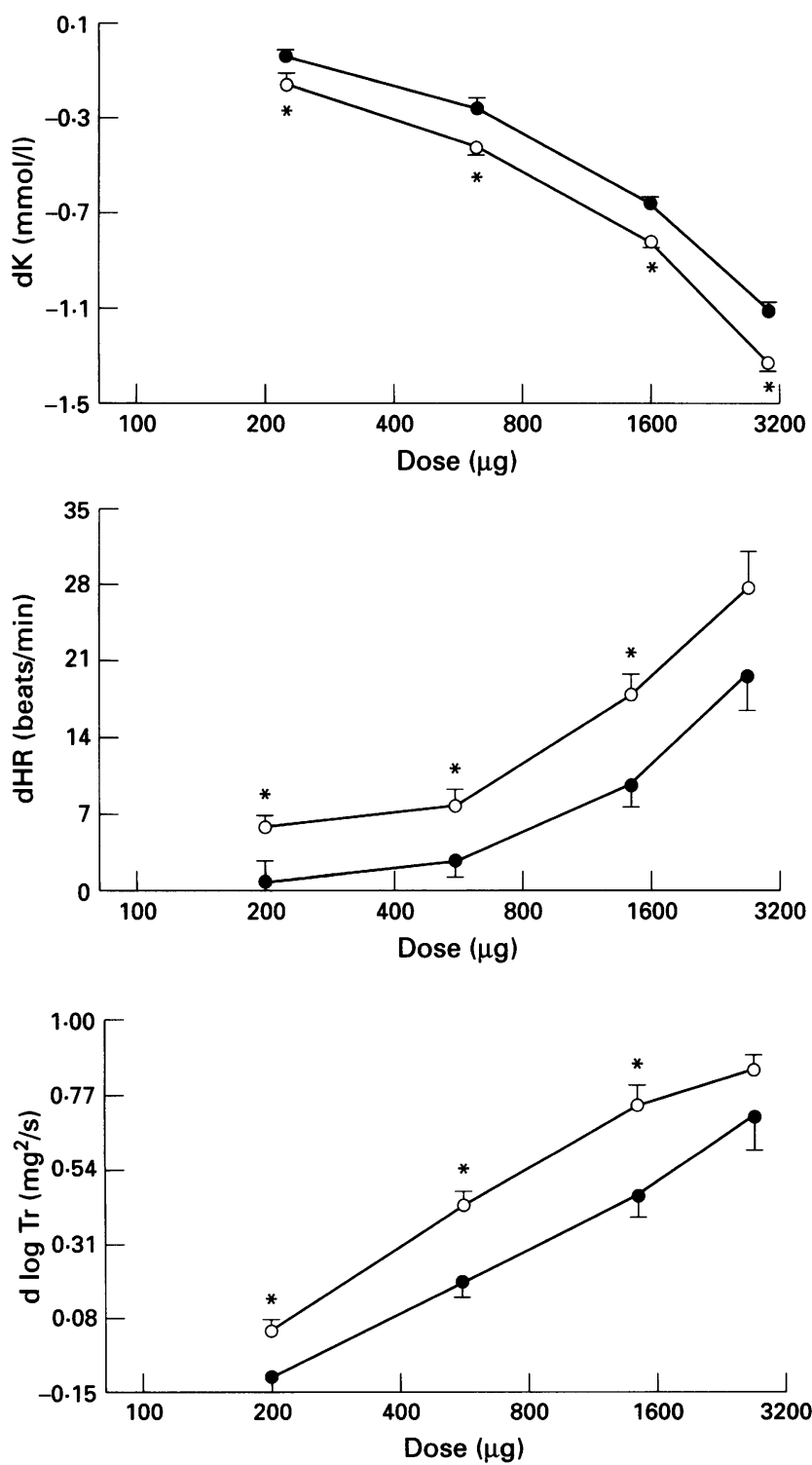

Figure 4 Dose-response curves with salbutamol for systemic $\beta_{2}$ effects showing a left shift for the modified actuator device (O) in comparison with the metered dose inhaler (O). Asterisks denote a significant difference between the two devices at a given dose. Taken from ref 31 with permission from Blackwell Scientific Publications, Oxford, UK. availability between the two devices was somewhat surprising in that previous radiolabelled deposition data comparing the two devices had shown no differences in terms of either total or peripheral lung deposition, whilst the modified actuator reduced oropharyngeal deposition. ${ }^{32}$ Thus, if systemic absorption of salbutamol had occurred directly from the buccal cavity or from the gut after swallowing, one might have expected the modified actuator to have attenuated systemic salbutamol absorption which was clearly not the case. Furthermore, it is difficult to account for the enhanced absorption of salbutamol across the lung vascular bed on the basis of the radiolabelled deposition data showing comparable peripheral lung deposition. The inference is that it may not be possible to extrapolate directly from radiolabelled deposition data to compare two formulations of the same drug (for example, generic drugs) or two delivery systems. It should also be pointed out, however, that in a study comparing the radiolabelled deposition and urinary pharmacokinetic techniques using terbutaline via a Turbohaler, ${ }^{33}$ overall lung deposition was lower with the pharmacokinetic method (21\% versus $27 \%)$. There is further evidence to support the validity of the pharmacokinetic method from a study in which two nebulisers - the Hudson Updraft II and the Ventstream nebuliser system - were compared. ${ }^{34}$ Since the Ventstream produces a considerable increase in output of respirable particles as well as matching the nebuliser output to tidal flow rate, one might predict a difference in lung deposition between the two nebuliser systems. Using plasma salbutamol levels for the pharmacokinetic evaluation, deposition with the Ventstream system was enhanced with an approximate twofold improvement in lung delivery as assessed by comparison of the peak plasma concentration or area under the concentration-time profile.

The urinary pharmacokinetic method for evaluating lung bioavailability can be refined by using the "charcoal block" technique in which oral activated charcoal suspension is used for mouth rinsing and swallowing to obviate oral and gut bioavailability. This enables calculation of lung deposition if a standard radiolabelled intravenous injection of the same drug is used as a pharmacokinetic internal standard for comparison. In one such study the lung bioavailability of inhaled budesonide was calculated at a mean value of $32 \%$, with the corresponding figures for a metered dose inhaler being $18 \% .^{35}$ Corresponding values for total systemic bioavailability (lung plus gut) in the same study were $37 \%$ for the Turbohaler and $24 \%$ for the metered dose inhaler, giving a clear indication of relative lung versus gut bioavailability. Derom and coworkers, ${ }^{36}$ also using the charcoal block technique with inhaled terbutaline in a dose of $500 \mu \mathrm{g}$, found an approximately 2:1 ratio between the two devices, although values for lung bioavailability were lower at $22 \%$ and $9 \%$ for Turbohaler and metered dose inhaler respectively. Clearly, if these pharmacokinetic data are truly representative of lung delivery, then the corollary should be that there is also a $2: 1$ ratio in terms of efficacy. In this respect the bronchodilator response to salbutamol shows a relative dose equivalence of $50 \mu \mathrm{g}$ versus $100 \mu \mathrm{g}$ and $200 \mu \mathrm{g}$ versus $400 \mu \mathrm{g}$ for Turbohaler and metered dose inhaler respectively. ${ }^{37}$ In another study in subjects with acute asthma the bronchodilator response to terbutaline $5.0 \mathrm{mg}$ was found to be twice as great with Turbohaler as with a Nebuhaler spacer device. ${ }^{38}$ Unfortunately there are no direct comparisons between Turbohaler and metered dose inhaler using the technetium radiolabelling method, although lung deposition data from different studies with these two devices 1628 would certainly not predict the $2: 1$ ratio obtained with the pharmacokinetic method. Furthermore, in the study by Melchor et $a l,{ }^{16}$ although total and peripheral lung de- 
position with the large volume spacer was significantly better than with the Diskhaler, this was not associated with any difference in bronchodilator response to $200 \mu \mathrm{g}$ inhaled salbutamol, once again possibly questioning the validity of the radiolabelled deposition technique.

\section{Other factors affecting lung deposition and bioavailability}

From first principles one might expect that lung deposition, and hence lung bioavailability, might be altered in patients with airflow obstruction as a consequence of narrowed peripheral airway calibre and reduced access to the alveolar vascular bed. This indeed appeared to be the case in the study of Melchor et $a l^{16}$ where peripheral lung deposition was significantly higher in normal subjects than in asthmatic patients, and this difference was uniformly observed with the metered dose inhaler, large volume spacer, and Diskhaler delivery systems. Despite an approximately twofold greater baseline $\mathrm{FEV}_{1}$ in normal compared with asthmatic subjects, the difference in lung deposition between the two groups was approximately 1.5-fold. Unfortunately there is no similar comparison between normal and asthmatic subjects in terms of lung bioavailability using the pharmacokinetic technique. There is, however, some indirect evidence - albeit from two different studies - comparing the pharmacokinetic profile of $4 \mathrm{mg}$ inhaled fenoterol in normal and asthmatic subjects using identical metered dose inhaler devices. ${ }^{30}{ }^{39} \mathrm{The} \mathrm{FEV}_{1}$, expressed as percentage predicted, was $56 \%$ in the asthmatic subjects and was associated with an approximate two-fold difference in peak plasma fenoterol concentration $(1.6 \mathrm{ng} / \mathrm{ml}$ in asthmatics and $3.1 \mathrm{ng} / \mathrm{ml}$ in the normal subjects). Indeed, the difference in plasma fenoterol levels between the two groups was associated with a marked difference in the maximal heart rate response to fenoterol $4 \mathrm{mg}$, being greater in the normal subject group. It is also evident that enhanced systemic absorption across the lung vascular bed is associated with increased $\beta_{2}$-mediated systemic effects, as was shown by Newnham et al in a study comparing the metered dose inhaler and modified actuator device (fig 4). ${ }^{31}$

For delivery of high doses of inhaled corticosteroid the routine use of a large volume spacer has been advocated, not only to reduce local side effects such as candidiasis but also to reduce systemic absorption from the oropharynx and gut. The net result of adding a large volume spacer will depend upon the relative effects of the spacer on lung and gut bioavailability. For example, Melchor et al, ${ }^{16}$ using radiolabelled salbutamol in asthmatic patients, showed that there was a mean reduction in gut deposition from $50 \%$ to $6 \%$ along with a concomitant increase in peripheral lung deposition (as a percentage total) from $30 \%$ to $39 \%$. Toogood et $a l^{40}$ calculated potency ratios for inhaled budesonide given via a pear-shaped spacer in comparison with a metered dose inhaler and showed a reduction in oropharyngeal candidiasis, increased delivery to the lung as assessed by peak flow measurements and spirometry, as well as an increase in systemic bioactivity as assessed by effects on early morning serum cortisol levels and blood eosinophil count. The increased systemic bioactivity using the pear-shaped spacer attachment is perhaps not entirely surprising since net gains from enhanced lung deposition would be expected to outweigh net losses from attenuated oral deposition. This study therefore further supports the hypothesis that lung bioavailability is the major determinant of systemic bioactivity.

In a study reported by Brown and coworkers ${ }^{41}$ in asthmatic patients taking high doses of either inhaled budesonide or beclomethasone dipropionate $(>1 \mathrm{mg} /$ day $)$ a comparison was made of adrenal suppression using a metered dose inhaler with or without a large volume spacer. The results showed no difference between the metered dose inhaler and spacer groups in terms of the proportion of cases with adrenal suppression, or in terms of the dose of inhaled corticosteroid causing suppression. Data from the same laboratory in normal volunteers comparing metered dose inhaler and large volume spacer for delivery of $2 \mathrm{mg} /$ day of either budesonide or beclomethasone dipropionate showed conflicting results. ${ }^{42}$ Beclomethasone dipropionate given by metered dose inhaler produced significant suppression of 24 hour urinary free cortisol excretion compared with placebo, and this effect was almost completely abolished by the large volume spacer used in conjunction with beclomethasone. It was not possible to make any inference on the effects of the large volume spacer on budesonide bioavailability because the metered dose inhaler on its own did not significantly suppress urinary free cortisol compared with placebo. This effect of the large volume spacer with beclomethasone dipropionate was also shown in asthmatic subjects in terms of producing reduced adrenal suppression with the spacer device. ${ }^{43}$ One possible explanation to account for the apparent discrepancy between beclomethasone dipropionate and budesonide might be that the reduction in oral and gut bioavailability with the spacer would be relatively more important for beclomethasone in view of its lesser degree of hepatic first-pass metabolism. In other words, with beclomethasone dipropionate using the large volume spacer, the net loss from gut bioavailability would outweigh the net gain from lung bioavailability with a resultant overall reduction in total systemic absorption.

\section{Conclusions and the way forward}

There is accumulating evidence from pharmacokinetic studies to suggest that absorption across the lung vascular bed is an important determinant of systemic bioactivity and adverse effects, this being particularly the case with inhaled corticosteriods where there is extensive first-pass metabolism in the liver but not in the lung. As a result the development of new inhaler delivery systems with improved lung deposition may increase systemic bioactivity at the same time as increasing topical airway activity. The use of pharmacokinetic evaluation may also reliably predict lung deposition for drugs such as inhaled $\beta_{2}$ agonists and corticosteroids where it is possible to quantify lung bioavailability. In this respect, studies are needed to compare directly the pharmacokinetic and radiolabelling methods for evaluating lung deposition and to compare these techniques in both normal and narrowed airways. The pharmacokinetic technique may also be applicable to the evaluation of the bioequivalence of generic inhaled drug formulations. For the future it is also possible that the inhaled route of administration might be used for systemic administration of certain drugs via the lung vascular bed, particularly where a rapid onset of action without firstpass metabolism is required as, for example, with a nicotine inhaler delivery system.

Department of Clinical Pharmacology,

Ninewells Hospital and Medical School,

B J LIPWORTH University of Dundee,

Dundee DD1 $95 Y$

$U K$

Lipworth BJ. Clinical pharmacology of corticosteroids in bronchial asthma Pharmacol Ther 1993;58:173-209.

Lipworth BJ. Risks versus benefits of inhaled $\beta_{2}$-agonists in the management of asthma. Drug Safety 1992;7:54-70.

Geddes DM. Inhaled corticosteroids: benefits and risks. Thorax 1992;47: 404-7. Monson JP. Systemic effects of inhaled corticosteroids. Thorax 1993;48:
955-6. 
5 Motwani JG, Lipworth BJ. Clinical pharmacokinetics of drugs administered buccally and sublingually. Clin Pharmacokinet 1991;21:83-4.

6 Lipworth BJ, Clark RA, Dhillon DP, Moreland TA, Struthers AD, Clark GA, et al. Pharmacokinetics, efficacy and adverse effects of sublingual salbutamol in patients with asthma. Eur f Clin Pharmacol 1989;37:567-71.

7 Collier JG, Dobbs RJ, Williams I. Salbutamol causes a tachycardia due to the inhaled rather than the swallowed fraction. Br f Clin Pharmacol 1980; 9:273-4.

8 Kung M, Croley SW, Phillips BA. Systemic cardiovascular and metabolic effects associated with the inhalation of albuterol; influence of mouth rinsing and gargling. Chest 1987;91:382-7.

9 Lipworth BJ, McDevitt DG, Struthers AD. Systemic $\beta$-adrenoceptor responses to salbutamol given by metered-dose inhaler alone and with pear-shaped spac pear-shaped

Morgan DJ, Paull JD, Richmond BJ, Wilson-Evered E, Ziccone SP. Pharmacokinetics of intravenous and oral salbutamol and its sulphate Pharmacokinetics of intravenous and oral salbutan

11 Martin LE, Harrison C, Tanner RJN. Metabolism of beclomethasone dipropionate by animals and man. Postgrad Med f 1975;51(Suppl 4): $11-20$

12 Ryrfeldt A, Andersson P, Edsbacker S, Tonnesson M, Davies D, Pauwels R. Pharmacokinetics and metabolism of budesonide, a selective glucocorticoid. Eur F Respir Dis 63:(Suppl 122):86-95.

13 Harding SM. The human pharmacology of fluticasone propionate. Respir Med 1990;84(Suppl A):25-9.

14 Selroos $\mathrm{O}$, Hulme $\mathbf{M}$. Effect of a volumatic spacer and mouth rinsing on systemic absorption of inhaled corticosteriods from a metered-dose inhaler and dry powder inhaler. Thorax 1991;46:891-4.

15 Pedersen S, Steffensen G, Ohlsson SV. The influence of orally deposited budesonide after inhalation from a Turbuhaler. Br f Clin Pharmacol 1993; 36:211-4.

16 Melchor R, Biddiscome MF, Mak VHF, Short MD, Spiro SG. Lung deposition patterns of directly labelled salbutamol in normal subjects and in patients with reversible airflow obstructions. Thorax 1993;48: and in

17 Grahnén A, Eckernas SA, Brundin RM, Ling-Andersson A. An assessment of the systemic activity of single doses of inhaled fluticasone propionate in healthy volunteers. Br 7 Clin Pharmacol 1994;38:521-5.

18 Grove A, Allam C, McFarlane LC, McPhate G, Jackson CM, Lipworth BJ. A comparison of the systemic bioactivity of inhaled budesonide and fluticasone propionate in normal subjects. Br f Clin Pharmacol 1994;38: 527-32.

19 Bain BM, Harrison G, Jenkins KD, Pateman AJ, Shenoy EVB. A sensitive radioimmunoassay, incorporating solid-phase extraction, for fluticasone 17-propionate in plasma. $f$ Pharmaceut Biomed Analysis 1993;11:557-61.

20 Johansson SA, Anderson FE, Brattsand R, Gruvstad E, Hedner P. Topical and systemic glucocorticoid potencies of budesonide and beclomethasone dipropionate in man. Eur $\mathcal{f}$ Clin Pharmacol 1982;22:523-9.

21 Phillips GH. Structure-activity relationships of topically active steroids: the selection of fluticasone propionate. Respir Med 1990;84(Suppl A): 19-23.

22 Andersson N, Klint S, Randwall G, Wiren JE. Equipotency of budesonide and fluticasone propionate in the vasoconstrictor assay. Thorax 1994;49: 422P.

23 Fabbri L. Burge PS, Croonenborgh L, Warlies F, Weeke B, Ciaccia A, et al. Comparison of fluticasone propionate with beclomethasone dipropionate in moderate to severe asthma treated for one year. Thorax propionate in mode

24 Bakke P, Boe J, Rodolen T, Skovlund E, Gulsvik A. Fluticasone propionate $2.0 \mathrm{mg}$ daily suppresses the hypothalamo-pituitary adrenal axis in mod- erate to severe asthmatics. Am $\mathcal{f}$ Respir Crit Care Med 1994;149(Suppl): A215.

25 Barnes NC, Marone G, Di Maria GU, Visser S, Utama I, Payne Sl. A comparison of fluticasone propionate, $1 \mathrm{mg}$ daily, with beclomethasone dipropionate, $2 \mathrm{mg}$ daily, in the treatment of severe asthma. Eur Respir $\mathcal{F}$ dipropionate, 2 m

26 Newman SP, Millar AB, Lennard-Jones TR, Moren F, Clarke SW. Improvement of pressurised aerosol deposition with nebuhaler spacer device. Thorax 1984;39:935-41.

27 Newman SP, Weisz AWB, Talaee N, Clarke SW. Improvement of drug delivery with a breath actuated pressurised aerosol for patients with poor inhaler technique. Thorax 1991;46:712-6.

28 Borgstrom L, Bondesson E, Moren F, Trofast E, Neuman SP. Lung deposition of budesonide inhaled via Turbohaler: a comparison with terbutaline sulphate in normal subjects. Eur Respir $\mathcal{F}$ 1994;7:69-73.

29 Hindle $M$, Chrystyn $H$. Determination of the relative bioavailability of salbutamol to lung following inhalation. Br $\mathcal{f}$ Clin Pharmacol 1992;34: 311-5.

30 Newnham DM, Wheeldon NM, Lipworth BJ, McDevitt DG. Single dosing comparison of the relative cardiac $\beta_{1} / \beta_{2}$ activity of inhaled fenoterol and comparison of the relative cardiac $\beta_{1} / \beta_{2}$ activity of inh
salbutamol in normal subjects. Thorax 1993;48:656-8.

31 Newnham DM, McDevitt DG, Lipworth BJ. Comparison of the extrapulmonary $\beta_{2}$-adrenoceptor responses and pharmacokinetics of salbutamol given by standard metered-dose inhaler and modified actuator device. Br f Clin Pharmacol 1993;36:445-50.

32 Newman SP, Clarke SW. Bronchodilator delivery from Gentlehaler, a new low-velocity pressurised aerosol inhaler. Chest 1993;103:1422-46.

33 Borgstrom L, Newnham S, Weisz A, Moren F. Pulmonary deposition of inhaled terbutaline: comparison of scanning gamma camera and urinary excretion methods. F Pharm Sci 1992;81:753-5.

34 Newnham DM, Lipworth BJ. Nebuliser performance, pharmacokinetics, airways and systemic effects of salbutamol given via a novel nebuliser airways and systemic effects of salbutamol given via

35 Thorsson L, Edsbacker S. Lung deposition of budesonide from turbohaler is twice that from a pressurised metered-dose inhaler (pMDI). Thorax 1993;48:L434P

36 Derom E, Wahlin-Boll E, Borgstrom L, Pauwels R. Pulmonary deposition and effect of terbutaline administered by metered dose inhaler or Turbohaler. Thorax 1994;49:402P.

37 Lofdahl CG, Andersson L, Carlsson LG, Firberg K, Hornblad Y, Jemsby $P$, et al. Lower nominal dose required of inhaled salbutamol via turbuhaler compared with pressurised metered dose inhaler, for the same bronchodilating effect. Am ₹ Respir Crit Care Med 1994;149:A219.

38 Tonnesen F, Laursen LC, Evald T, Stahl E, Ibsa TB. Bronchodilating effect of terbutaline powder in acute severe bronchial obstruction. Chest 1994;105:697-700.

39 Lipworth BJ, Newnham DM, Clark RA, Dhillon DP, Winter JH, McDevitt DG. Comparison of the relative airways and systemic potencies of inhaled fenoterol and salbutamol in asthmatic patients. Thorax 1995;50:54-61.

40 Toogood JH, Baskerville J, Jennings B, Lefcoe NM, Johansson SA. Use of spacers to facilitate inhaled corticosteroid treatment of asthma. $\mathrm{Am}$ Rev Respir Dis 1984;129:723-9.

41 Brown PA, Greening AP, Crompton GK. Large volume spacer devices and the influence of high dose beclomethasone depropionate or hypothalamopituitary-adrenal axis function. Thorax 1993;48:233-8.

42 Brown PH, Matusiewicz SP, Shearing C, Tibi L, Greening AP, Crompton GK. Systemic effects of high dose inhaled steroids: comparison of beclomethasone dipropionate and budesonide in healthy subjects. Thorax 1993;48:967-73.

43 Brown PH, Blundell G, Greening AP, Crompton GK. Do large volume spacer devices reduce the systemic effects of high dose inhaled corticosteroids? Thorax 1990;45:736-9. 